\title{
An expert-supported monitoring system for patients with chronic obstructive pulmonary disease in general practice: results of a cluster randomised controlled trial
}

\author{
Lisette van den Bemt, Tjard R J Schermer, Ivo J M Smeele, Leandra J M Boonman-de Winter, Ton van Boxem, \\ Joke Denis, Joke G Grootens-Stekelenburg, Richard P T M Grol and Chris van Weel
}

$\mathrm{R}$ apid changes in general practice have increased possibilities to diagnose and manage chronic diseases such as chronic obstructive pulmonary disease (COPD). Several national and international guidelines for COPD are available ${ }^{1-4}$ to help general practitioners with this.

"Monitoring", or regular surveillance of patients' health status, is a cornerstone of COPD management. ${ }^{5}$ Input of specialist knowledge into monitoring enables comparison of the process and outcome of care with evidence-based guidelines. It can also alert GPs to areas in which individual patient care falls short, and introduce explicit recommendations for management. Our group has demonstrated the effectiveness of expertsupported monitoring on the outcome of diabetes care in general practice. ${ }^{6}$

COPD management places a substantial demand on medical resources, ${ }^{7,8}$ and patient adherence is important to the success of treatment. ${ }^{9}$ Any expert-supported respiratory monitoring system depends on the cooperation of various groups (ie, GPs, specialists and patients), contains interacting components, and is, therefore, a complex intervention. ${ }^{10}$

We aimed to investigate the long-term effectiveness of a primary care monitoring system with respiratory expert recommendations for GPs' management of patients with COPD, compared with usual care. We performed a detailed process evaluation along with the trial; elements of this evaluation are also reported here.

\section{METHODS}

\section{Study design}

We conducted a multicentre parallel group study with a 24-month patient follow-up (www.clinicaltrials.gov NCT00542061). The trial took place from July 2005 to February 2008. We allocated general practices to intervention (ie, respiratory expertsupported COPD monitoring system) or usual care. All participants at each general practice were allocated to the same treatment group (cluster randomised design).

\section{ABSTRACT}

Objective: To investigate the long-term effectiveness of a general practice monitoring system with respiratory expert recommendations for general practitioners' management of patients with chronic obstructive pulmonary disease (COPD), compared with usual care.

Design, settings and participants: A multicentre randomised controlled trial of patients with COPD, clustered by general practices; 200 participants were recruited to maintain at least 75 participants per group for analysis. The trial took place from July 2005 to February 2008 in the south-western region of the Netherlands.

Intervention: Ongoing half-yearly monitoring of COPD patients with respiratory expert recommendations for the GP was compared with usual care.

Main outcome measures: Primary outcome - Chronic Respiratory Questionnaire (CRQ) score; secondary outcomes - CRQ domain scores, generic health-related quality of life (Short-Form 12 and EuroQol-5D), breathlessness (Modified Medical Research Council score), exacerbations, and decline in forced expiratory volume in 1 second. A detailed process evaluation was performed along with the trial.

Results: Data from 170 participants were analysed. Based on repeated measurement analyses, the additional gain in CRQ score during follow-up was 0.004 points for monitoring compared with usual care $(95 \% \mathrm{Cl},-0.172$ to 0.180$)$. Also, no important differences between monitoring and the usual care group were found for secondary outcomes. Half the monitoring visits resulted in disease management recommendations by a respiratory expert, and $46 \%$ of these recommendations were implemented by the GPs. Patient adherence to lifestyle recommendations was low.

Conclusion: An expert-supported monitoring system for patients with COPD was not clinically effective. As patients had a pre-existing entry in the monitoring system, the population may be well regulated, with reduced room for improvement.

Trial registration: www.clinicaltrials.gov NCT00542061.

MJA 2009; 191: 249-254

We hypothesised that ongoing half-yearly monitoring with respiratory expert recommendations of patients with COPD would result in a clinically relevant gain in quality of life compared with usual care.

The study protocol was approved by the medical ethics committee of the Arnhem Nijmegen region in the Netherlands. All patients gave written informed consent.

\section{Participants and sample size calculation}

We selected and invited study participants based on patient records already available at a regional diagnostic centre (RDC) in the south-western region of the Netherlands.

Inclusion criteria were:

- patient diagnosed with COPD or asthma with persistent airflow obstruction, as confirmed with the patient's most recent spirometry (forced expiratory volume in 1 second $\left[\mathrm{FEV}_{1}\right] /$ forced vital capacity [FVC] $<70 \%$, or postbronchodilator $\mathrm{FEV}_{1}<80 \%$ predicted and $\geqslant 9 \%$ reversibility); ${ }^{11,12}$

- the patient's lung function data from the previous year were available at the general practice diagnostic centre; and

- patient aged at least 25 years.

Exclusion criteria were:

- patient treated by a chest physician;

- patient participating in another respiratory intervention study;

- GP considered it detrimental to the patient to participate in the study;

- patient had any serious other nonpulmonary diseases (or disease stages) or pulmonary diseases (eg, sarcoidosis, lung cancer, lung fibrosis); or

- patient could not read. 
1 Flow chart of practice and participant recruitment, inclusion and drop-out

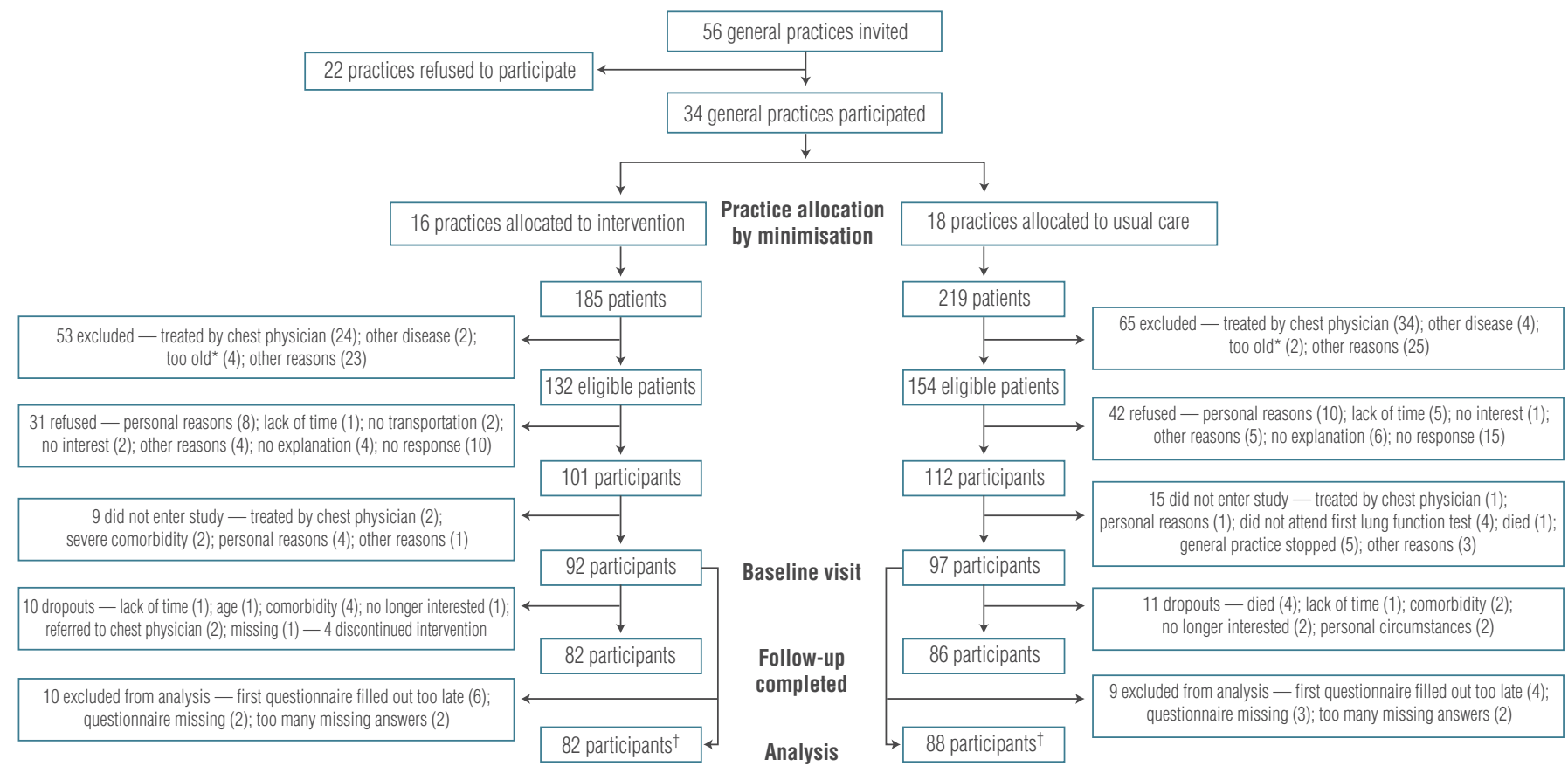

* According to the patient's general practitioner. $†$ Analyses were based on the intention-to-treat principle.

GPs at practices who had referred more than six patients to the RDC were contacted and asked to participate. We used computerised minimisation to allocate practices to the monitoring and usual care groups ${ }^{13,14}$ while stratifying for:

- group versus solo practice;

- practice nurse employed versus no practice nurse employed; and

- $\leqslant 10$ versus >10 patients fulfilling the study inclusion criteria.

A multilevel power calculation (ie, correction for clustering of subjects within general practices) was based on the mean difference in change in Chronic Respiratory Questionnaire (CRQ) score between monitoring and usual care. A difference of 0.5 points is generally accepted as a minimum important clinical difference for the CRQ score. ${ }^{15}$ We initially aimed to recruit 100 participants per group based on the following assumptions: an intracluster correlation coefficient of $0.04 ; \alpha=0.05 ; 1-\beta=0.80$; and a dropout rate of $25 \%$.

\section{Blinding}

In their study information letters, GPs and patients were informed that patients were invited for an unspecified number of visits to the RDC. GPs were informed that participation could imply that the outcome of their patients' visits would not be forwarded to them during the study as it had been previously. After minimisation, GPs received specific research information for their practice. The respiratory experts involved and the lung function technicians who performed the spirometric tests and collected medical information were not aware of patients' participation and allocation.

\section{Intervention}

The expert-supported COPD monitoring system had been in use in the RDC since 1995, and comprised several steps.

Step A. Patients with COPD were invited to the RDC for monitoring visits every 6 months. Pre- and post- (after inhaling $400 \mu \mathrm{g}$ salbutamol) bronchodilator $\mathrm{FEV}_{1}$ and FVC were measured at each visit with a SpiroPerfect spirometer (WelchAllyn, Delft, The Netherlands) by certified lung function technicians. Body mass index was assessed, and information on respiratory symptoms, exacerbations, smoking and medication use in the previous 6 months was collected in a standardised way.

Step B. Information from the monitoring visit and previous visits was sent to a respiratory expert (chest physician or GP with special respiratory interest). The respiratory experts gave recommendations regarding treatment, additional diagnostic tests and referrals to other disciplines, based on national clinical practice guidelines for COPD and asthma. ${ }^{11,12}$ Experts' interpretation based on spirometry results and written information has been shown to be valid. ${ }^{16}$

Step C. Written feedback was sent to the patient's GP. The patient was instructed to visit the GP 2 weeks after the monitoring visit to discuss the outcome. During these visits, the expert recommendations could be implemented by the GP (eg, checking inhalation technique) or recommended to the patient. Half-yearly visits from a nurse consultant to the practice to support GPs in implementing the recommendations were an integral part of the expert-supported monitoring system.

Step D. Ultimately, the patient should implement the recommendations made (eg, quit smoking, increase exercise).

\section{Usual care}

We invited participants from the usual care group for spirometry at the beginning and at the end of the trial. No recommendations or feedback were given, and no nurse consultant practice visits were scheduled during the study period.

\section{Outcomes and process evaluation}

Participants completed questionnaires at baseline, at 1 year, and at the end of the 


\begin{tabular}{|c|c|c|}
\hline \multicolumn{3}{|c|}{$\begin{array}{l}2 \text { Baseline characteristics } \\
\text { of participants }\end{array}$} \\
\hline & $\begin{array}{c}\text { Monitoring } \\
\text { group } \\
(n=82)\end{array}$ & $\begin{array}{c}\text { Usual care } \\
\text { group } \\
(n=88)\end{array}$ \\
\hline $\begin{array}{l}\text { Age in years, } \\
\text { mean (SD) }\end{array}$ & $62(10.5)$ & $64(10.5)$ \\
\hline Male & $56^{*}$ & 47 \\
\hline $\begin{array}{l}\text { Post-BD FEV }{ }_{1} \% \text { of } \\
\text { predicted }\end{array}$ & $70^{\dagger \neq}$ & 77 \\
\hline Post-BD FEV $1 / F V C$ & $61^{\star \ddagger}$ & 65 \\
\hline Short-acting BDs & $33^{\ddagger}$ & 26 \\
\hline Long-acting BDs & $52^{\ddagger}$ & 58 \\
\hline ICS & $59^{\ddagger}$ & 65 \\
\hline \multicolumn{3}{|l|}{ Smoking } \\
\hline Yes & $53^{\dagger}$ & 40 \\
\hline No & 6 & 18 \\
\hline Former smoker & 23 & 30 \\
\hline $\begin{array}{l}\text { Pack-years, } \\
\text { mean (SD) }\end{array}$ & $27.5(21.8)^{\star}$ & $20.7(18.1)$ \\
\hline \multicolumn{3}{|l|}{ MMRC score } \\
\hline 0 & $11^{\ddagger}$ & 16 \\
\hline 1 & 36 & 30 \\
\hline 2 & 26 & 35 \\
\hline 3 & 6 & 5 \\
\hline $4-5$ & 2 & 2 \\
\hline $\begin{array}{l}\geqslant 1 \text { exacerbations } \\
\text { in past year }\end{array}$ & $16^{\S}$ & 17 \\
\hline
\end{tabular}

$\mathrm{BD}=$ bronchodilator. $\mathrm{FEV}_{1}=$ forced expiratory volume in 1 second. $F V C=$ forced vital capacity. ICS $=$ inhaled corticosteroids. MMRC $=$ Modified Medical Research Council. * Difference between monitoring group and usual care group significant; $P<0.05$. $†$ Difference between monitoring group and usual care group significant; $P<0.01$. $¥$ One missing value. §Two missing values.

study. The primary study outcome was the CRQ score. ${ }^{17}$ Secondary outcomes were: CRQ domain scores; generic health-related quality of life (physical and mental domains of the Short-Form 12 [SF-12] and the EuroQol-5D); ${ }^{18-20}$ breathlessness according to level of exertion (Modified Medical Research Council [MMRC] score, ${ }^{2}$ dichotomised as 0-1 and 2-4); occurrence rate of selfreported exacerbations; and annual $\mathrm{FEV}_{1}$ decline.

For the process evaluation, the respiratory experts' database was examined to collect data on their recommendations. The nurse consultant collected data on GPs' implementation of recommendations. Patient questionnaires comprised questions about disease management. At the end of the study, the nurse consultant collected infor- mation on disease management from GPs in the usual care group.

\section{Statistical analysis}

Baseline characteristics for the participants in each group were compared using unpaired $t$ tests, $\chi^{2}$ tests, and Mann-Whitney $U$ tests, depending on the type of variable and normality of distribution.

Multilevel repeated measurement regression analysis was used to model the effect of monitoring on CRQ overall score, CRQ domain scores, SF-12 scores, EuroQol-5D scores, $\mathrm{FEV}_{1}$ decline, and dichotomised MMRC scores. We used a PROC MIXED procedure in SAS statistical software (SAS Institute, Cary, NC, USA), with general practice as the random coefficient and compound symmetry correlation structure. Multilevel logistic regression analysis was used to analyse effects on exacerbations. All models were corrected for sex, age, socioeconomic status, baseline cigarette smoking status, reversibility, exacerbations at baseline, use of inhaled corticosteroids, use of long-acting bronchodilators, and postbronchodilator $\mathrm{FEV}_{1} \%$ of the predicted value. Participants were included in the analysis if they participated in the study (intention-to-treat analysis).

\section{RESULTS}

\section{Study population}

Box 1 shows the process of practice and patient recruitment and follow-up. Thirtyfour general practices participated. From these, 261 of 286 eligible patients (91\%) responded to the invitation, and 213 (74\%) were willing to participate. No significant differences between participants and non-participants with regard to sociodemographic characteristics, medication use, and spirometric indices were found. Twenty-four patients did not enter the study, and 19 patients were excluded from analyses. Data from 170 participants were used for the analyses. Box 2 shows the baseline characteristics of both groups.

The study was originally designed to evaluate monitoring of patients with COPD and asthma with a chronic airflow obstruction. However, after the recruitment phase we found that almost all of the patients fulfilled the criteria for COPD (ie, $\mathrm{FEV}_{1} / \mathrm{FVC}<70 \%$ postbronchodilator); therefore, we decided to focus on COPD.

\section{Clinical effectiveness of the expert- supported monitoring system}

Box 3 shows the mean overall CRQ scores in the monitoring and usual care groups. Based on repeated measurement analyses, the additional gain in CRQ score during followup was 0.004 points for monitoring compared with usual care $(95 \% \mathrm{CI},-0.172$ to 0.180 ). Box 4 summarises the results for the secondary outcomes. No significant differences between the monitoring and usual care groups were observed other than CRQ domain mastery.

\section{Process evaluation}

A total of 292 visits took place among the monitoring group participants. Fifty-eight participants attended all four planned monitoring visits at the RDC (71\%). Fifteen patients (18\%) attended three, six patients attended two, and three patients attended one planned visit.

In total, respiratory experts gave 290 recommendations (Box 5). Smoking cessation was the most frequent recommendation (28\% of all recommendations), and inhaler technique training and assessment of compliance with medical treatment were also recommended regularly. In 146 monitoring visits (50\%), the respiratory experts did not consider any modification in disease management necessary. For 73 patients (89\%), the GPs received at least one recommendation to change disease management.

Information about 274 of the 290 recommendations could be collected (Box 5). According to GPs, they attempted to implement 125 (46\%) of the 274 recommenda-

\section{Mean CRQ score $(95 \% \mathrm{Cl})$ of expert-supported COPD monitoring compared with usual care at baseline and at 1 and 2 years}

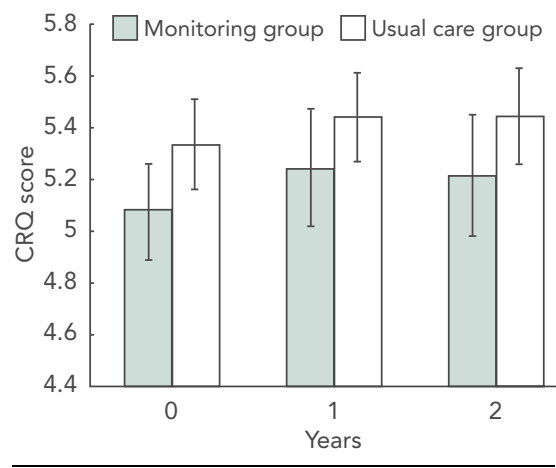

COPD = chronic obstructive pulmonary disease. $\mathrm{CRQ}=$ Chronic Respiratory Questionnaire. 
4 Effects of expert-supported chronic obstructive pulmonary disease monitoring compared with usual care on outcomes of respiratory health and quality of life

A. Mean $(95 \% \mathrm{Cl})$ at baseline, change $(95 \% \mathrm{Cl})$ at follow-up, and difference between groups $(95 \% \mathrm{Cl})$ for continuous variables

\begin{tabular}{|c|c|c|c|c|c|c|}
\hline & \multicolumn{2}{|c|}{ Monitoring group } & \multicolumn{2}{|c|}{ Usual care group } & \multirow[b]{2}{*}{$\begin{array}{c}\text { Adjusted incremental } \\
2 \text {-year change* }\end{array}$} & \multirow[b]{2}{*}{ MICD } \\
\hline & $\begin{array}{l}\text { Baseline } \\
(n=82)\end{array}$ & $\begin{array}{l}\text { Change at 2-year } \\
\text { follow-up }(n=76)\end{array}$ & $\begin{array}{l}\text { Baseline } \\
(n=88)\end{array}$ & $\begin{array}{l}\text { Change at 2-year } \\
\text { follow-up }(n=80)\end{array}$ & & \\
\hline Overall CRQ score & 5.1 (4.9 to 5.3$)$ & $0.12(-0.02$ to 0.26$)$ & 5.3 (5.2 to 5.5$)$ & $0.12(0.00$ to 0.24$)$ & & \\
\hline CRO domain dyspnoea & $4.9(4.6 \text { to } 5.3)^{\dagger}$ & 0.30 (0.10 to 0.50$)$ & $5.4(5.1 \text { to } 5.7)^{\ddagger}$ & $0.29(0.07 \text { to } 0.50)^{\ddagger}$ & $0.018(-0.24$ to 0.27$)$ & 0.5 \\
\hline $\mathrm{CRO}$ domain fatigue & 4.9 (4.7 to 5.2$)$ & $-0.09(-0.32$ to 0.13$)$ & 5.1 (4.9 to 5.3 ) & $0.13(-0.09$ to 0.34$)$ & $-0.236(-0.54$ to 0.07$)$ & 0.5 \\
\hline CRQ domain emotions & 5.4 (5.2 to 5.6$)$ & $0.08(-0.11$ to 0.27$)$ & 5.5 (5.3 to 5.7$)$ & $0.09(-0.06$ to 0.24$)$ & $-0.005(-0.26$ to 0.25$)$ & 0.5 \\
\hline CRQ domain mastery & $4.8(4.7 \text { to } 5.0)^{\S}$ & 0.17 (0.02 to 0.33$)$ & 5.1 (4.9 to 5.3 ) & $-0.03(-0.16$ to 0.11$)$ & $0.223^{\dagger}$ (0.02 to 0.42$)$ & 0.5 \\
\hline SF-12 physical scale & $44.5(43.0 \text { to } 46.1)^{n}$ & $-1.44(-2.98 \text { to } 0.10)^{\ddagger}$ & $43.8(42.3 \text { to } 45.4)^{\star \star}$ & $-0.16(-1.73 \text { to } 1.42)^{\dagger \dagger}$ & $-1.323(-3.40$ to 0.75$)$ & $3-5$ \\
\hline SF-12 mental scale & $52.2(50.2 \text { to } 54.1)^{\pi}$ & $0.09(-1.85 \text { to } 2.03)^{\ddagger}$ & $52.7(51.1 \text { to } 54.2)^{\star \star}$ & $-0.23(-1.94 \text { to } 1.49)^{\dagger \dagger}$ & 0.324 (-2.24 to 2.89$)$ & $3-5$ \\
\hline EuroQol-5D score & 0.89 (0.86 to 0.92$)$ & $-0.02(-0.05$ to 0.01$)$ & 0.87 (0.84 to 0.89$)$ & 0.00 (-0.03 to 0.03$)$ & -0.022 (-0.07 to 0.02$)$ & 0.07 \\
\hline
\end{tabular}

B. Frequency (no. [\%]) of categorical variables at baseline and follow-up, and odds ratios

\begin{tabular}{|c|c|c|c|c|c|}
\hline & \multicolumn{2}{|c|}{ Monitoring group } & \multicolumn{2}{|c|}{ Usual care group } & \multirow{2}{*}{$\begin{array}{c}\text { Odds ratio } \\
(95 \% \mathrm{Cl})\end{array}$} \\
\hline & Baseline $(n=82)$ & 2-year follow-up $(n=76)$ & Baseline $(n=88)$ & 2-year follow-up $(n=80)$ & \\
\hline MMRC score $\geqslant 2$ & $8(9.9 \%)^{9}$ & $12(15.8 \%)$ & $7(8.0 \%)$ & $10(12.7 \%)^{9}$ & $1.05(0.34-3.24)$ \\
\hline$\geqslant 1$ exacerbations in previous year & $16(20.0 \%)^{\ddagger}$ & 12 (15.8\%) & $17(19.8 \%)^{\ddagger}$ & $10(12.7 \%)^{n}$ & $0.87^{\text {㧊}}(0.38-2.11)$ \\
\hline
\end{tabular}

$\mathrm{CRQ}=$ Chronic Respiratory Questionnaire. SF-12=Short-Form 12. MICD = minimum important clinical difference. MMRC=Modified Medical Research Council.

* Monitoring versus usual care based on multilevel repeated measurement analysis corrected for sex, age, socioeconomic status, smoking status at baseline, reversibility,

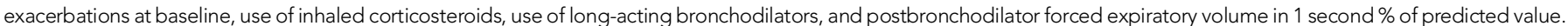
†Difference between monitoring and usual care is significant; $P<0.05$. $¥$ Two missing values. $\S$ Difference between monitoring and usual care is significant; $P<0.01$.

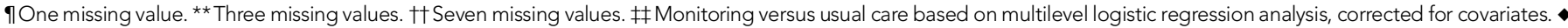

5 Number of times a respiratory expert recommended each disease management change, and general practitioner adherence to recommendations overall and in practices with and without a practice nurse

\begin{tabular}{|c|c|c|c|c|c|}
\hline \multirow[b]{2}{*}{ Recommendation } & \multirow[b]{2}{*}{$\begin{array}{l}\text { Expert } \\
\text { recommend- } \\
\text { ations }\end{array}$} & \multirow[b]{2}{*}{$\begin{array}{c}\text { Recommend- } \\
\text { ations } \\
\text { evaluated* }\end{array}$} & \multicolumn{3}{|c|}{ GPs' adherence } \\
\hline & & & Overall & $\begin{array}{c}\text { Practices } \\
\text { with } \\
\text { nurse }^{\dagger}\end{array}$ & $\begin{array}{c}\text { Practices } \\
\text { without } \\
\text { nurse }^{\dagger}\end{array}$ \\
\hline Cease smoking & 82 & 78 & 44 & $25 / 47$ & $19 / 31$ \\
\hline Optimise physical condition & 21 & 20 & 6 & $2 / 5$ & $4 / 15$ \\
\hline Avoid allergens and triggers & 4 & 4 & 3 & $1 / 1$ & $2 / 3$ \\
\hline Check inhaler technique & 47 & 45 & 21 & $15 / 23$ & $6 / 22$ \\
\hline Check treatment compliance & 49 & 46 & 29 & $18 / 25$ & $11 / 21$ \\
\hline Reduce bodyweight & 4 & 3 & 1 & $1 / 2$ & $0 / 1$ \\
\hline Introduce ICS & 15 & 14 & 5 & $2 / 7$ & $3 / 7$ \\
\hline Increase ICS dosage & 6 & 6 & 3 & $1 / 2$ & $2 / 4$ \\
\hline Reduce dosage or cease ICS & 10 & 10 & 6 & $6 / 10$ & $0 / 0$ \\
\hline Introduce short-acting BD & 1 & 1 & 1 & $1 / 1$ & $0 / 0$ \\
\hline Introduce long-acting BD & 10 & 8 & 0 & $0 / 4$ & $0 / 4$ \\
\hline Additional diagnostic procedures & 3 & 3 & 0 & $0 / 2$ & $0 / 1$ \\
\hline Chest x-ray & 14 & 13 & 3 & $1 / 8$ & $2 / 5$ \\
\hline Refer to chest physician & 24 & 23 & 3 & $1 / 9$ & $2 / 14$ \\
\hline Total & 290 & 274 & 125 & $74 / 146^{\ddagger}$ & $51 / 128$ \\
\hline
\end{tabular}

Adherence $=$ GP attempted to implement recommendation. BD = bronchodilator. ICS $=$ inhaled corticosteroids. * Eleven recommendations were not discussed by GPs and three GPs' responses were missing. † No. of GPs adhering to recommendation/no. of recommendations evaluated in each type of practice. $\ddagger$ Difference between practices with and without practice nurses is significant; $P<0.05$ ( $\chi^{2}$ test). tions. In practices with a practice nurse, the implementation rate of recommendations was higher than in practices without a practice nurse $(P<0.05)$; in particular, inhaler technique training and checking medication compliance were implemented more frequently (Box 5). The main reason why recommendations were not implemented was because patients did not visit the practice after their monitoring visit at the RDC. On 45 occasions, patients did not visit the GP after a monitoring visit that had resulted in at least one recommendation.

Changes in disease management are shown in Box 6. In general, only minor changes in disease management were achieved in the monitoring group, and these changes were comparable to usual care.

\section{DISCUSSION}

We did not find a clinical benefit for patients who received ongoing care according to a well structured respiratory expert-supported COPD monitoring system compared with usual care by GPs. The adherence of patients to the monitoring visits was good. In half the cases, the respiratory experts felt that disease management could be improved, and almost half the recommenda- 
6 Chronic obstructive pulmonary disease management by general practitioners and patients in the second year of the study

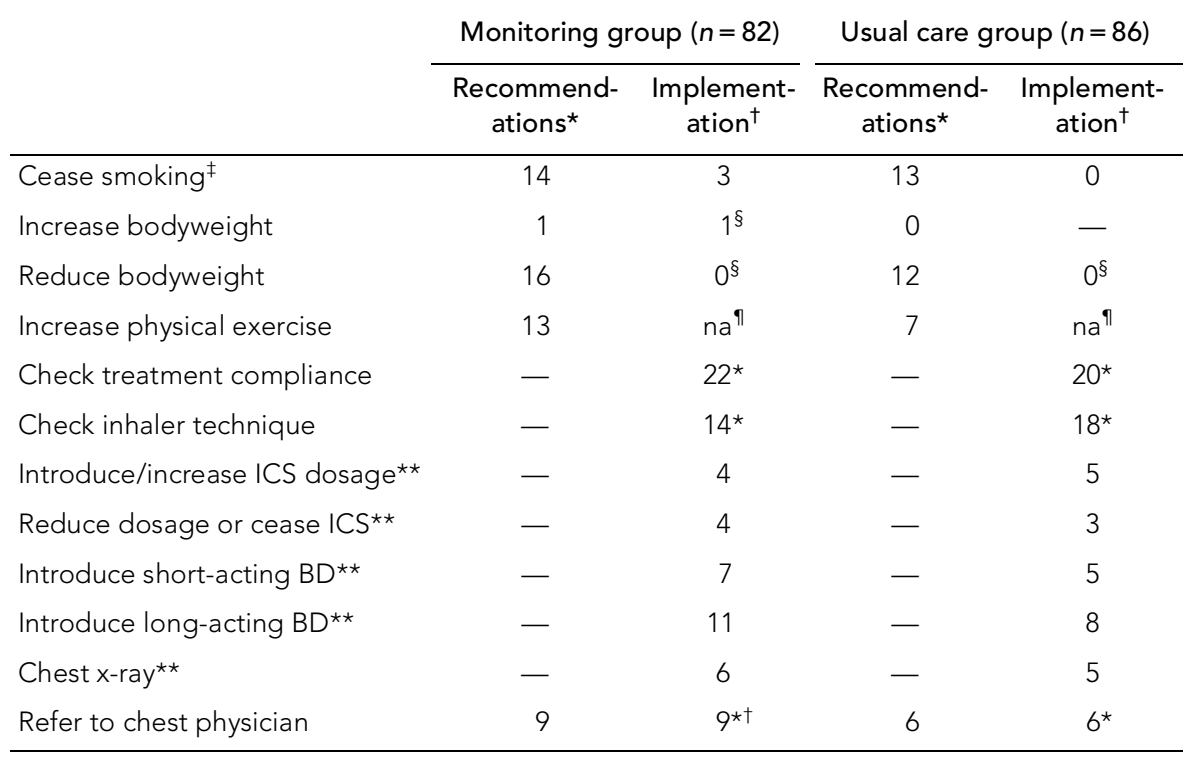

$\mathrm{BD}=$ bronchodilator. ICS $=$ inhaled corticosteroids. na = not applicable. Recommendations = by GPs. In monitoring group, these were based on expert recommendation or own initiative.

* According to the patient. † Implementation of recommendations by the patient. $\neq$ Patient stopped smoking according to the last questionnaire and medical information of the last visit to the regional diagnostic centre. $\S \pm 3 \mathrm{~kg}$ bodyweight change according to measurement during lung function visits. II Information on exercise tolerance was not collected. ** According to GPs' electronically recorded information (nine missing values in monitoring group; 10 missing values in usual care group).

tions by respiratory experts were implemented by GPs. Non-adherence of patients to visiting the GPs and making lifestyle changes, and the low adherence of GPs to some recommendations (eg, referral to chest physician, chest $\mathrm{x}$-ray) were the main barriers to the implementation of the expert recommendations.

All patients who were invited had previously visited the diagnostic centre for at least one lung function assessment. It may be argued that we did not find effects in the study because we studied the effect of monitoring on a population with pre-existing entry into the monitoring system, rather than the effect of monitoring on a newly diagnosed population. Essentially, we compared health effects in a control group that had discontinued monitoring with those in the treatment group that had continued and intensified monitoring. This might have resulted in less "room for improvement" compared with a "naive" population of COPD patients. The inclusion of newly diagnosed patients could have resulted in better clinical results. However, our aim was to determine the long-term usefulness of disease monitoring. The evaluated monitoring system has already been implemented on a large scale in the Netherlands, and after patients with COPD have entered the service, they are usually followed for many years. Our results indicate that keeping an expertsupported monitoring system in place for years appears not to benefit COPD patients.

Moreover, it was not possible to blind GPs and patients in this study, as information on process and outcome was reported by them. Patients who are aware of their treatment assignment may expect certain benefits that may influence the outcome, especially when the outcome is influenced by individual opinions, as with quality of life. However, monitoring group participants reported no higher health-related quality-of-life scores compared with usual care group participants.

As far as we are aware, this is the first time the effectiveness of a COPD expert-supported monitoring system has been evaluated. However, other programs that focus on monitoring, like an integrated COPD and/or asthma management care model, a GP feedback system, and monitoring of healthrelated quality of life of patients with asthma and COPD, also did not result in clinical benefits, although some improvements in patient satisfaction and process outcomes were found. ${ }^{21-24}$ Other monitoring systems, such as monitoring of COPD by respiratory nurses in a general practice or a "patient- tailored" monitoring system, should be explored. Moreover, more information on the initial effect of the expert-supported monitoring system in newly diagnosed patients is needed (ie, including patients who were not already known to the RDC). It may be that the support system is able to put COPD management on track, and that after this initial support, GPs are sufficiently equipped to manage the patients.

The question remains whether the lack of effect was due to implementation failure and therefore the system has the potential to be effective if implementation could be improved — or was a result of an ineffective intervention. ${ }^{10}$ Many participants failed to visit the GP, although the adherence rate to GP visits was significantly higher in general practices that invited patients for regular visits. Moreover, the presence of a practice nurse resulted in higher implementation levels. Therefore, implementation can be improved, but it is not possible to fully prevent dilution of effects in the process of monitoring and feedback. Options to reduce disease progression are limited in COPD. ${ }^{25,26}$ Moreover, little evidence exists that chronic disease management in primary care patients with COPD is effective. ${ }^{27}$ Potential effects are further diminished by the low adherence of the participants to health behaviour recommendations, which is in concordance with other studies. ${ }^{25,28}$

In conclusion, an ongoing respiratory expert-supported monitoring system for patients with COPD was not effective in terms of clinical outcomes. The lack of effectiveness may have been the result of a combination of limited options to intervene, the diluting effect on the intervention caused by the many steps in this complex process, and the low adherence of patients to crucial recommendations such as smoking cessation.

\section{ACKNOWLEDGEMENTS}

We thank the employees of the Stichting Huisartsen Laboratorium (SHL, diagnostic centre, Breda) who were involved in the lung function service of the $\mathrm{SHL}$ and therefore responsible for the collection of the data presented in the article. Moreover, we are very grateful to all the participants and GPs. Special thanks go to Reinier Akkermans (statistician). Finally, we would like to thank "Partners in Care Solutions for COPD" (PICASSO) for their financial support, which enabled us to conduct this study.

\section{COMPETING INTERESTS}

None identified. 


\section{AUTHOR DETAILS}

Lisette van den Bemt, MSc, Researcher ${ }^{1}$ Tjard R J Schermer, PhD, Research Coordinator

Ivo J M Smeele, MD, PhD, General Practitioner and Advisor, COPD Service ${ }^{2}$

Leandra J M Boonman-de Winter, MSc,

Research Coordinator, Department of Scientific and Contract Research (WECOR) ${ }^{2}$

Ton van Boxem, MD, PhD, Chest Physician ${ }^{3}$

Joke Denis, Asthma and COPD Consultant and

Lung Function Technician ${ }^{2}$

Joke G Grootens-Stekelenburg, Data

Manager ${ }^{1}$

Richard PT M Grol, PhD, Professor and $\mathrm{Head}^{4}$

Chris van Weel, MD, FRCGP, FRACGP,

Professor and Head, ${ }^{1}$ and President, World

Organization of Family Doctors (Wonca)

1 Department of Primary and Community Care,

Centre for Family Medicine, Geriatric Care

and Public Health, Radboud University

Nijmegen Medical Centre, Nijmegen,

The Netherlands.

2 Centre for Diagnostic Support in Primary

Care (SHL), Etten-Leur, The Netherlands.

3 Franciscus Hospital, Roosendaal,

The Netherlands.

4 IQ healthcare, Radboud University Nijmegen

Medical Centre, Nijmegen, The Netherlands.

Correspondence: I.vandenbemt@elg.umcn.nl

\section{REFERENCES}

1 McKenzie DK, Abramson M, Crockett AJ, et al. The COPD-X Plan: Australian and New Zealand guidelines for the management of chronic obstructive pulmonary disease 2009. http:// www.copdx.org.au/guidelines/index.asp (accessed Jul 2009).

2 GOLD - the global initiative for chronic obstructive lung disease [website]. http:// www. goldcopd.com (accessed Jan 2008).

3 National Institute for Health and Clinical Excellence. Chronic obstructive pulmonary disease: management of chronic obstructive pulmonary disease in adults in primary and secondary care. London: NICE, 2004.
4 Smeele IJM, van Weel C, van Schayck CP, et al. [Dutch College of General Practitioners guidelines for COPD] [Dutch]. Huisarts Wet 2007; 50: 362-379.

5 van den Bemt L, Schermer T, Smeele I, et al. Monitoring of patients with COPD: a review of current guidelines' recommendations. Respir Med 2008; 102: 633-641.

6 de Grauw WJ, van Gerwen WH, van de Lisdonk $\mathrm{EH}$, et al. Outcomes of audit-enhanced monitoring of patients with type 2 diabetes. J Fam Pract 2002; 51: 459-464.

7 Hoogendoorn M, Rutten-van Molken MP, et al. A dynamic population model of disease progression in COPD. Eur Respir J 2005; 26: 223233.

8 Pauwels RA, Rabe KF. Burden and clinical features of chronic obstructive pulmonary disease (COPD). Lancet 2004; 364: 613-620

9 Ramsey SD. Suboptimal medical therapy in COPD: exploring the causes and consequences. Chest 2000; 117 (2 Suppl): 33S-37S.

10 Craig P, Dieppe P, Macintyre S, et al. Developing and evaluating complex interventions: the new Medical Research Council guidance. BMJ 2008; 337: a1655.

11 Geijer RMM, van Schayck CP, van Weel C, et al. [Dutch College of General Practitioners guidelines for COPD: treatment] [Dutch]. Huisarts Wet 2001; 44: 207-219.

12 Geijer RMM, van Hensbergen W, Bottema BJAM, et al. [Dutch College of General Practitioners guidelines for asthma in adults: treatment] [Dutch]. Huisarts Wet 2001; 44: 153-164.

13 Pocock SJ, Simon R. Sequential treatment assignment with balancing for prognostic factors in the controlled clinical trial. Biometrics 1975; 31: 103-115.

14 Altman DG, Bland JM. Treatment allocation by minimisation. BMJ 2005; 330: 843

15 Redelmeier DA, Guyatt GH, Goldstein RS. Assessing the minimal important difference in symptoms: a comparison of two techniques. J Clin Epidemiol 1996; 49: 1215-1219.

16 Lucas A, Smeenk F, Smeele I, et al. The validity of diagnostic support of an asthma/COPD service in primary care. Br J Gen Pract 2007; 57: 892-896

17 Williams JE, Singh SJ, Sewell L, et al. Development of a self-reported Chronic Respiratory
Questionnaire (CRQ-SR). Thorax 2001; 56: $954-$ 959.

18 EuroQol - a new facility for the measurement of health-related quality of life. The EuroQol Group. Health Policy 1990; 16: 199-208.

19 Ware J Jr, Kosinski M, Keller SD. A 12-item Short-Form Health Survey: construction of scales and preliminary tests of reliability and validity. Med Care 1996; 34: 220-233.

20 Lamers LM, Stalmeier PF, McDonnell J, et al. [Measuring the quality of life in economic evaluations: the Dutch EQ-5D tariff] [Dutch]. Ned Tijdschr Geneeskd 2005; 149: 1574-1578.

21 Meulepas MA, Jacobs JE, Smeenk FW, et al. Effect of an integrated primary care model on the management of middle-aged and old patients with obstructive lung diseases. Scand J Prim Health Care 2007; 25: 186-192.

22 Jacobs JE, van de Lisdonk EH, Smeele I, et al. Management of patients with asthma and COPD: monitoring quality of life and the relationship to subsequent GP interventions. Fam Pract 2001; 18: 574-580.

23 Jacobs JE. Patient-tailored monitoring of patients with asthma and COPD [thesis]. Nijmegen, The Netherlands: Radboud University Medical Centre, 2006.

24 Smeele IJM. Improving care for patients with asthma and COPD in general practice [thesis]. Nijmegen, The Netherlands: Radboud University Medical Centre, 1999.

25 Kotz D, Wesseling G, Huibers MJ, van Schayck OC. Efficacy of confronting smokers with airflow limitation for smoking cessation. Eur Respir J 2009; 33: 754-762.

26 Anthonisen NR, Skeans MA, Wise RA, et al. The effects of a smoking cessation intervention on 14.5-year mortality: a randomized clinical trial. Ann Intern Med 2005; 142: 233-239.

27 Cranston JM, Crockett AJ, Moss JR, et al. Models of chronic disease management in primary care for patients with mild-to-moderate asthma or COPD: a narrative review. Med J Aust 2008; 188 (8 Suppl): S50-S52.

28 Bourbeau J, Bartlett SJ. Patient adherence in COPD. Thorax 2008; 63: 831-838.

(Received 13 Apr 2009, accepted 19 Jun 2009)

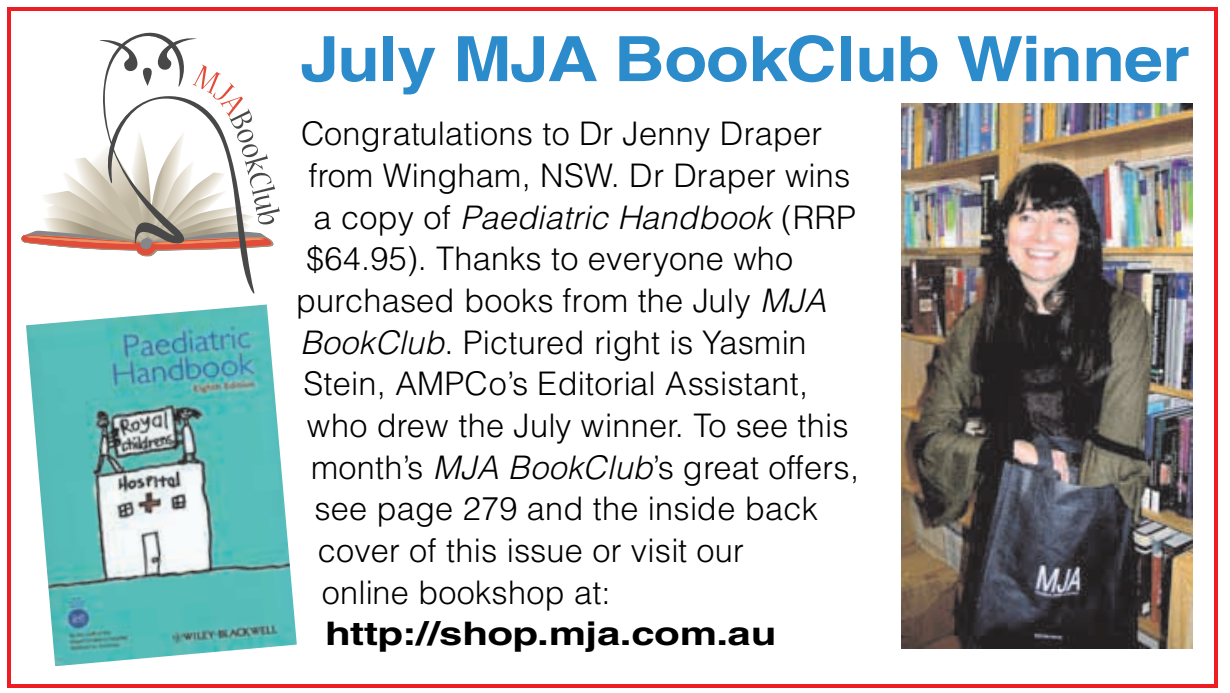

